\title{
Effects of Urban Transportation Infrastructure Development Projects on Residential Land Price in Cau Giay District, Hanoi City
}

\author{
Le Phuong Thuy, Bui Ngoc Tu, Pham Le Tuan, Tran Quoc Binh*
}

VNU University of Science, 334 Nguyen Trai, Hanoi, Vietnam

Received 09 December 2020

Revised 02 January 2020; Accepted 08 January 2020

\begin{abstract}
Urban transportation infrastructure development projects usually act as a lever for real estate values. This research aims to assess the effects of some projects on urban land prices in three wards of Cau Giay District, namely Quan Hoa, Dich Vong, and Dich Vong Hau wards. With 161 samples surveyed, we established a multivariate linear regression model initially having 11 variables. As the result, six variables are identified as having significant effect on land prices in the study area. Among those, three variables are related to the local transportation infrastructure, namely: location of land parcels; distance to urban railway lines; and distance to public transport stations. Location of land parcels and distance to public transport stations are factors that have a significant influence in reality. Besides, the distance to the urban railway lines is the factor that has a positive impact on land prices, but it is only still a potential and should be extensively investigated in the future because the urban railway project is still in the implementation phase.
\end{abstract}

Keywords: Urban transportation infrastructure, urban residental land prices, Cau Giay District.

\footnotetext{
* Corresponding author.

E-mail address: binh.geomatics@gmail.com 


\title{
Ảnh hưởng của dự án phát triển hạ tầng giao thông đô thị đến giá đất ở tại khu vực quận Cầu Giấy, thành phố Hà Nội
}

\author{
Lê Phương Thúy, Bùi Ngọc Tú, Phạm Lê Tuấn, Trần Quốc Bình* \\ Truờng Đại học Khoa học Tụ nhiên, Đại học Quốc gia Hà Nội, 334 Nguyễn Trãi, Hà Nội, Việt Nam \\ Nhận ngày 09 tháng 12 năm 2019 \\ Chỉnh sửa ngày 02 tháng 01 năm 2020; Chấp nhận đăng ngày 08 tháng 01 năm 2020
}

\begin{abstract}
Tóm tắt: Các dự án phát triển hạ tầng giao thông đô thị được ví như chiếc đòn bẩy cho giá trị của các bất động sản. Nghiên cứu này nhằm mục tiêu đánh giá ảnh hưởng của một số dự án đối với giá đất ở đô thị trên địa bàn 03 phường của quận Cầu Giấy là: Quan Hoa, Dịch Vọng và Dịch Vọng Hậu. Với bộ dữ liệu 161 mẫu điều tra, nghiên cứu xây dựng mô hình hồi quy đa biến tuyến tính với 6 biến ảnh hưởng đến giá đất thuộc khu vực nghiên cứu. Trong đó có 3 biến liên quan đến dự án phát triển hạ tầng giao thông là vị trí, khoảng cách đến đường sắt trên cao, và khoảng cách đến trạm giao thông công cộng. Yếu tố vị trí và khoảng cách đến trạm giao thông công cộng có ảnh hưởng rõ rệt trong thực tế. Yếu tố khoảng cách đến đường sắt đô thị mặc dù có ảnh hưởng tích cực đến giá đất nhưng sự ảnh hưởng này cần được xem xét đầy đủ hơn do dự án vẫn đang trong giai đoạn thực hiện.
\end{abstract}

Từ khoá: hạ tầng giao thông đô thị, giá đất ở đô thị, quận Cầu Giấy.

\section{Mở đầu}

Hạ tầng giao thông có vai trò đặc biệt quan trọng đối với sự phát triển kinh tế - xã hội, tạo động lực và là cầu nối cho sự phát triển của các ngành kinh tế cũng như đời sống xã hội. Trong lĩnh vực bất động sản, nó được ví như "chiếc đòn bẩy" cho giá trị bất động sản. Ronghui Tan và cộng sự (2019) đã chỉ ra trong phạm vi $1600 \mathrm{~m}$ từ các ga tàu điện ngầm mới tại Vũ Hán, Trung Quốc, giá nhà đất có thể có giá trị cao hơn $7 \%$ - 14\% so với các bất động sản ở xa hơn [1]. Ở một phân tích tổng hợp theo các mức khoảng cách và loại bất động sản khác nhau, nghiên cứu của Debrezion và các cộng sự (2007) cho thấy các nhà ga đường sắt có ảnh hưởng làm tăng giá của bất động sản sử dụng cho mục đích thương mại chỉ thấy rõ ở khoảng cách ngắn. Trong khi đó, ảnh hưởng của ga đường sắt đến giá của bất động sản sử dụng cho mục đích để ở vẫn thấy rõ trên các khoảng cách xa [2]. Các hướng nghiên cứu thể hiện ảnh hưởng tích cực của các dự án phát triển hạ tầng giao thông đến giá bất động sản còn được kể đến là Du và Mulley (2012) [3], Chen và cộng sự (1997) [4]. Những lợi ích của việc tăng giá trị đất khi có tác động từ các dự án phát triển hạ tầng giao thông đô thị có ý nghĩa quan trọng, vì đó là nguồn lực tiềm năng để đầu tư trở lại cho hạ tầng. Khái niệm này được gọi là nắm bắt giá trị đất, hay thu nhận giá trị đất (Land Value Capture - LVC).

Bên cạnh những tác động tích cực (làm tăng giá bất động sản) thì còn có một số nghiên cứu đề cập đển những tác động tiêu cực, làm giảm giá bất động sản, ví dụ như sự gia tăng của tiếng ồn, tỷ lệ tội phạm cao hơn ở một mức độ nào đó [5]. Chen và cộng sự (1997) chỉ ra mặc dù khả năng tiếp cận đến nhà ga của hệ thống Portland MAX LRT có ảnh hưởng tích cực nhiều hơn là

\footnotetext{
* Tác giả liên hệ.

Địa chỉ email: binh.geomatics@gmail.com

https://doi.org/10.25073/2588-1094/vnuees.4522
} 
tiêu cực đến giá bất động sản, nhưng nghiên cứu vẫn nhấn mạnh tầm quan trọng của việc tính đến các ảnh hưởng tiêu cực tùy thuộc vào loại hệ thống giao thông công cộng [4]. Ngoài ra, nhóm tác giả cũng đưa ra giả thuyết là khoảng cách đến các tuyến đường sắt (khoảng cách thẳng theo đường chim bay) có thể đem lại ảnh hưởng tiêu cực, làm giảm giá bất động sản [4]. Lawless và Gore (1999) cũng tìm thấy tác động tiêu cực làm giảm giá nhà trong giai đoạn triển khai dự án phát triển giao thông tại Sheffield, UK, nhưng điều này đã mất đi sau khi dự án được hoàn thành [6].

Ở Việt Nam, nhiều nghiên cứu thực hiện phân tích sự ảnh hưởng của yếu tố cơ sở hạ tầng giao thông thường gắn liền với các nghiên cứu về các yếu tố ảnh hưởng đến giá nhà đất nói chung, trong đó có yếu tố về vị trí của bất động sản. Nguyễn Mạnh Hùng và nhóm nghiên cứu (2008) đã xây dựng mô hình hồi quy cho hơn 300 mẫu nhà ở được khảo sát tại quận Thủ Đức, Bình Thạnh và quận 1 . Kết quả cho thấy giá nhà ở phụ thuộc vào các biến khoảng cách đến trung tâm thành phố, vị trí nhà mặt tiền hay trong hẻm, diện tích lô đất, số tầng xây dựng [7]. Nguyễn Quỳnh Hoa và Nguyễn Hồng Dương (2016) thể hiện các yếu tố về trục giao thông quan trọng của quận và trục giao thông quan trọng của thành phố ở dạng biến định tính trong mô hình thẩm định giá đất hàng loạt cho địa bàn quận Gò Vấp, thành phố Hồ Chí Minh [8]. Lê Phương Thúy và cộng sự (2018) cũng chỉ ra yếu tố vị trí, cấp đường có ảnh hưởng đến giá đất khu vực Trung Hòa - Nhân Chính, thành phố Hà Nội [9].

Nhìn chung, các nghiên cứu cho thấy tác động của dự án phát triển hạ tầng giao thông có cả mặt tích cực và tiêu cực. Phương pháp để đánh giá chủ yếu dựa trên phân tích hồi quy Hedonic [4,6,7], hồi quy trọng số địa lý GWR [3], hồi quy đa biến $[2,8]$, kết hợp với các công cụ hô̂ trợ phân tích không gian trong GIS [1,9]. Hầu hết các nghiên cứu đều sử dụng bộ dữ liệu liên quan đến giá bất động sản (bao gồm cả đất và nhà) để xem xét mối quan hệ với hạ tầng giao thông. Một nghiên cứu tổng quan của Ingvardson J.B. và Nielsen, O. A. (2018) chỉ ra không có phương pháp tiêu chuẩn chung để tính toán sự thay đổi trong giá cả bất động sản. Do đó, các nghiên cứu khác nhau sử dụng nhiều phương pháp và nguồn dữ liệu sao cho phù hợp với đặc điểm của địa phương và bởi vì các dự án giao thông được phát triển cũng tùy thuộc vào các khu vực khác nhau [5].

Những năm gần đây, Hà Nội đã được đầu tư nhiều dự án phát triển hạ tầng giao thông góp phần làm thay đổi diện mạo bộ mặt Thủ đô, như các dự án mở rộng đường phố, mở thêm các con đường mới và đặc biệt là dự án đường sắt đô thị trên cao. Khu vực quận Cầu Giấy là khu vực có tốc độ đô thị hóa nhanh, được đầu tư một số dự án như dự án đường Trần Đăng Ninh kéo dài, dự án đường Nguyễn Văn Huyên kéo dài, và tuyến đường sắt đô thị số 03 chạy qua,... Trong số đó, một số dự án đã được hoàn thành, còn dự án tuyến đường sắt đô thị vẫn đang trong giai đoạn thực hiện. Vì vậy, mục tiêu của nghiên cứu là xem xét tác động của các dự án phát triển hạ tầng giao thông đô thị này đến giá đất ở khu vực xung quanh thông qua phân tích hồi quy đa biến. Phạm vi của nghiên cứu áp dụng với đất ở đô thị, trong khi phần lớn các nghiên cứu trước chủ yếu áp dụng với giá bất động sản (bao gồm cả đất và nhà). Theo Du và Mulley (2007), sự thay đổi giá bất động sản đến từ giá trị của đất là chủ yếu và lớn hơn nhiều so với giá trị của công trình xây dựng nếu những công trình này không có những giá trị đặc biệt đối với thị trường [10].

\section{Phương pháp nghiên cứu}

Kế thừa từ các nghiên cứu thực nghiệm, nhóm tác giả sử dụng phương pháp nghiên cứu truyền thống là phân tích hồi quy đa biến với sự hỗ trợ của các phần mềm thống kê như SPSS, Eview và kết hợp với các công cụ hỗ trợ phân tích không gian của phần mềm ArcGIS.

Phân tích hồi quy đa biến là một phương pháp thống kê dùng để ước lượng giá trị của biến phụ thuộc dựa trên nhiều biến độc lập. Biến phụ thuộc (thường gọi là biến $\mathrm{Y}$ ) là biến được sử dụng để mô tả hoặc đo lường vấn đề nghiên cứu. Biến độc lập (thường gọi là biến $\mathrm{X}$ ) là các biến được sử dụng để mô tả hoặc đo lường các yếu tố 
được giả định là ảnh hưởng đến vấn đề nghiên cứu. Trong nghiên cứu này, giá đất được xác định là biến phụ thuộc và các yếu tố ảnh hưởng đến giá đất (trong đó có các yếu tố liên quan đến hạ tầng giao thông đô thị) là các biến độc lập.

Để thực hiện phân tích hồi quy, nghiên cứu đề xuất quy trình phân tích ở Hình 1.

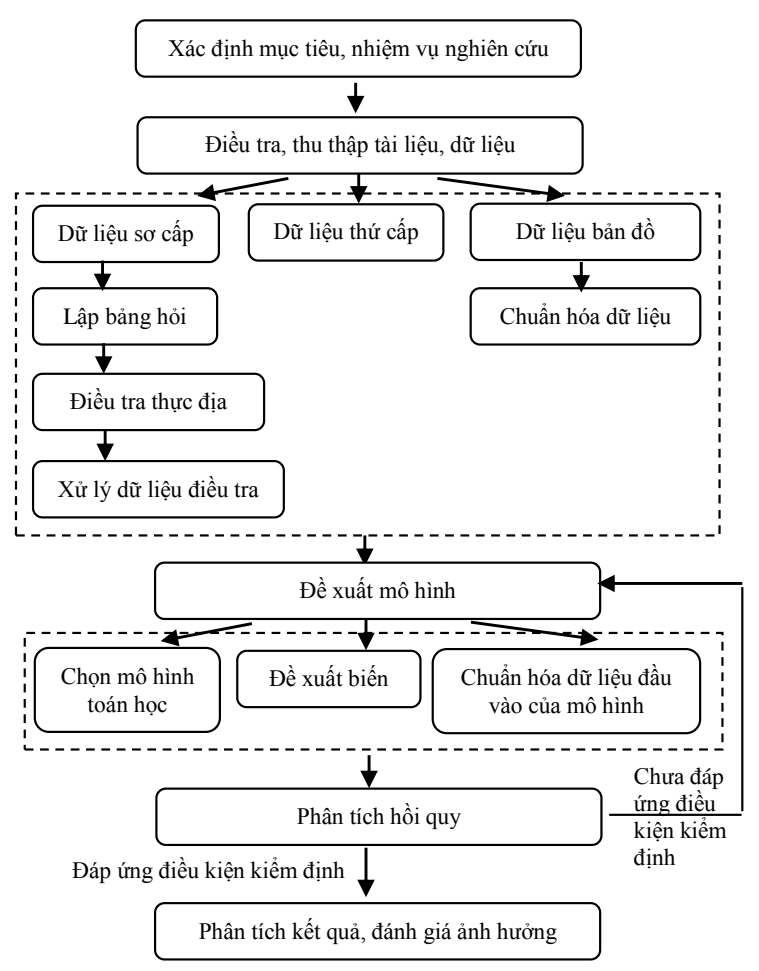

Hình 1. Quy trình phân tích.

- Xác định mục tiêu, nhiệm vụ nghiên cứu: Mục tiêu của nghiên cứu là xem xét ảnh hưởng tích cực và tiêu cực của dự án phát triển hạ tầng giao thông đô thị đến giá đất ở khu vực quận Cầu Giấy.

- Điều tra, thu thập tài liệu, dữ liệu: Đây là bước rất quan trọng, đóng vai trò là nguồn dữ liệu đầu vào cho phân tích. Các dữ liệu thu thập bao gồm dữ liệu sơ cấp, dữ liệu thứ cấp và dữ liệu bản đồ. Đối với dữ liệu sơ cấp, đề tài thực hiện thiết kế một bảng hỏi gồm 45 câu với các thông tin về thửa đất, nhà, hộ gia đình, và các đặc điểm lân cận để tiến hành điều tra khảo sát thực địa. Phương pháp điều tra được thiết kế theo các tuyến đường phố. Mỗi tuyến phố sẽ điều tra các thửa đất ở 4 vị trí theo phân loại hiện hành của Nhà nước: vị trí 1 áp dụng đối với thửa đất tiếp giáp với đường, phố; vị trí 2 áp dụng đối với thửa đất tiếp giáp với ngõ có độ rộng từ $3,5 \mathrm{~m}$ trở lên; vị trí 3 áp dụng đối với thửa đất tiếp giáp với ngõ có độ rộng từ $2 \mathrm{~m}$ đến dưới $3,5 \mathrm{~m}$; vị trí 4 áp dụng đối với thửa đất tiếp giáp với ngõ có độ rộng dưới $2 \mathrm{~m}$ [11]. Ở mỗi cấp độ vị trí ứng với một tuyến phố đã điều tra từ 1 đến 3 mẫu. Thời điểm giá đất giao dịch được giới hạn trong khoảng thời gian từ khoảng 1 năm trước thời điểm dự án phát triển giao thông đô thị được triển khai cho đến nay. Các nguồn thu thập số liệu có thể từ việc hỏi trực tiếp chủ nhà đất; thông qua đối tượng trung gian như hàng xóm, hoặc trung tâm môi giới bất động sản; các cơ quan nhà nước.

Sau khi điều tra thực địa, các tác giả tiến hành xử lý dữ liệu điều tra bao gồm: lọc những mẫu không đủ điều kiện như thời gian giao dịch quá xa, giá giao dịch không tin cậy; trường hợp mẫu thu thập bao gồm cả giá nhà và đất cần tính giá đất riêng bằng các phương pháp so sánh, phương pháp chiết trừ. Đối với dữ liệu thứ cấp, các tác giả thu thập báo cáo công tác bảo vệ môi trường trên địa bàn quận Cầu Giấy năm 2018 , còn đối với dữ liệu bản đồ, thu thập bản đồ địa chính dạng số và chuẩn hóa dữ liệu, tạo thành một cơ sở dữ liệu geodatabase trong phần mềm ArcGIS.

- Đề xuất mô hình: Để thực hiện phân tích hồi quy, cần xác định các biến số và đề xuất mô hình. Nguyễn Quỳnh Hoa và Nguyễn Hồng Dương (2016) đề cập rằng có 3 dạng mô hình phổ biến là mô hình cộng, mô hình nhân và mô hình hỗn hợp, trong đó mô hình cộng được sử dụng rộng rãi để thẩm định giá trị bất động sản dân cư [8]. Chi tiết hơn, qua nghiên cứu thực nghiệm, Morancho (2003), Król (2015) đề cập đển hàm toán học thường được sử dụng trong phân tích hồi quy bất động sản là dạng hàm tuyến tính thường, hàm bán logarit như log-lin hoặc lin-log, hàm log-log $[12,13]$. Trong nghiên cứu này, nhóm tác giả sử dụng mô hình tuyến tính thường để phân tích. Mồ hình tổng thể được thể hiện như sau: 


$$
\begin{aligned}
& Y_{i}=\alpha+\beta_{1} \mathrm{X}_{1 i}+\beta_{2} \mathrm{X}_{2 i}+\cdots+\beta_{k} \mathrm{X}_{k i}+\varepsilon_{i} \\
& i=1, \ldots, n
\end{aligned}
$$

trong đó: số);

$\alpha$ : tham số tự do (còn gọi là hệ số chắn, hằng

$\beta_{l, \ldots,} \beta_{k}$ : hệ số hồi quy riêng (hệ số hồi quy từng phần);

$n$ : cỡ mẫu;

$\mathcal{E}_{i}$ : sai số ngẫu nhiên.

Ngoài ra, tại bước này cần xác định và mô tả các biến cũng như dấu kỳ vọng của các biến. Số lượng các biến cần phù hợp với số lượng mẫu điều tra. Theo Samuel B. Green (1991), phần lớn các nghiên cứu lựa chọn cỡ mẫu $n>50+8 m$ cho phân tích hồi quy đa biến với $m$ là số lượng các biến độc lập [14]. Cơ sở để xác định các biến là rất quan trọng. Malpezzi (2002) cho rằng hàm Hedonic về cơ bản là hàm hồi quy của giá bất động sản với các thuộc tính là đơn vị cấu thành nên giá bất động sản. Hàm có dạng $\mathrm{R}=\mathrm{f}(\mathrm{S}, \mathrm{N}$, $\mathrm{L}, \mathrm{C}, \mathrm{T}$ ) trong đó $\mathrm{R}$ : giá bất động sản, $\mathrm{S}$ : các thuộc tính về cấu trúc, $\mathrm{N}$ : các thuộc tính lân cận, L: thuộc tính vị trí trong thị trường, $\mathrm{C}$ : điều kiện hợp đồng hay các tiện tích đi kèm, $\mathrm{T}$ : thời gian của giá bán được quan sát [15]. Tuy nhiên, để nghiên cứu được ảnh hưởng của các yếu tố hạ tầng giao thông đến giá đất thì trong hàm hồi quy, các biến số đại diện cho các yếu tố liên quan đến hạ tầng giao thông cần được tập trung hơn. Nhóm nghiên cứu xác định đó là những biến thể hiện sự ảnh hưởng tích cực (như khả năng tiếp cận của thửa đất đến các yếu tố hạ tầng giao thông, đến các địa điểm kinh tế xã hội) và những biến thể hiện sự ảnh hưởng tiêu cực (như tiếng ồn, bụi) đến giá đất. Vì vậy, những biến số liên quan đến yếu tố cá biệt của thửa đất như hình dạng, mặt tiền, diện tích sẽ không đề cập trong mô hình.

Nhiệm vụ cuối cùng trong bước đề xuất mô hình là chuẩn hóa dữ liệu đầu vào của mô hình. Cụ thể, nghiên cứu tiến hành hiệu chỉnh sự ảnh hưởng của các yếu tố cá biệt (yếu tố diện tích, hình dạng, mặt tiền) đến giá đất. Cách thức hiệu chỉnh dựa trên hệ số ảnh hưởng của các yếu tố cá biệt tính từ dữ liệu điều tra thực địa thông qua phương pháp so sánh cặp mẫu [16]. Đối với các yếu tố cần phân tích khoảng cách theo mạng lưới giao thông như quãng đường từ thửa đất đến ga tàu điện gần nhất, đến công viên gần nhất,... sẽ được phân tích bằng công cụ Network Analyst của phần mềm ArcGIS. Riêng biến số liên quan đến tiếng ồn và hàm lượng bụi lơ lửng được nội suy từ các điểm quan trắc ven các trục giao thông chính và khu dân cư trên địa bàn quận Cầu Giấy. Thời điểm quan trắc được thực hiện vào tháng 12/2018 [17]. Tất cả các dữ liệu thuộc tính của một mẫu điều tra sẽ được tổng hợp thành 1 file Excel để phục vụ cho phân tích thống kê.

- Phân tích hồi quy: Công cụ phân tích hồi quy được sử dụng trong phần mềm SPSS là Linear Regression. Kết quả của phân tích hồi quy sẽ cho ra các hệ số hồi quy và mức ý nghĩa thống kê (giá trị Sig.) của từng biến độc lập. Với những biến có mức ý nghĩa $\leq 0,05$ là đạt yêu cầu và được sử dụng trong mô hình hồi quy. Ngoài ra, trong phân tích hồi quy còn cần kiểm định các hiện tượng làm phá vỡ giả thuyết ban đầu của phương pháp này về tính độc lập của các biến:

+ Hiện tượng đa cộng tuyến là hiện tượng các biến có tương quan chặt, phụ thuộc lẫn nhau và thể hiện được dưới dạng hàm số, làm cho kết quả phân tích bị sai lệch. Một trong số những cách để phát hiện hiện tượng đa cộng tuyến là sử dụng giá trị VIF (Variance Inflation Factor, nhân tố phóng đại phương sai) trong bảng hồi quy SPSS. Nếu giá trị VIF <10 thì không có hiện tượng đa cộng tuyến [18].

+ Hiện tượng tự tương quan: là tồn tại mối quan hệ giữa các phần tử của chuỗi số liệu được sắp xếp theo thời gian hoặc không gian. Để phát hiện hiện tượng này, có thể sử dụng kiểm định Durbin Watson (gọi là giá trị $d$ ) trong phần mềm SPSS. Với mỗi cỡ mẫu $n$, số biến độc lập $k^{\prime}$ sẽ quy định giá trị $d_{L}$ và $d_{U}$ là các giá trị tới hạn của thống kê Durbin -Watson [19]. Nếu $d_{U}<d<4$ $d_{U}$ thì không có hiện tượng tự tương quan. Nếu $4-d_{L}<d<4$ hoặc $0<d<d_{L}$ thì có hiện tượng 
tự tương quan. Nếu $d_{L} \leq \mathrm{d} \leq d_{U}$ hoặc $4-d_{U} \leq \mathrm{d} \leq$ $4-d_{L}$ thì không quyết định [20].

Trong trường hợp các điều kiện kiểm định không đáp ứng, cần quay lại bước đề xuất mô hình để lựa chọn lại các biến và xác định lại mô hình. Nếu xuất hiện hiện tượng tự tương quan, có thể khắc phục bằng phương pháp sai phân bậc 1 (the first-difference method) $[8,20]$. Sau khi đáp ứng được các điều kiện, kêt quả sẽ cho ra các biến số ảnh hưởng đến giá đất ở đô thị cùng các hệ số hồi quy từng phần.

- Phân tích kết quả, đánh giá ảnh hưởng: Dựa trên giá trị và dấu của hệ số hồi quy từng phần, nghiên cứu thực hiện phân tích đánh giá mức độ ảnh hưởng của các yếu tố tới giá đất ở đô thị. Nếu dấu của hệ số hồi quy là dương, thể hiện chiều hướng ảnh hưởng thuận đến giá đất ở. Tức khi giá trị của biến số đó tăng thì làm tăng giá đất ở. Ngược lại, nếu dấu của hệ số hồi quy là âm, thể hiện chiều hướng ảnh hưởng nghịch đến giá đất ở. Tức khi giá trị của biến số đó tăng thì làm giảm giá đất ở. Lượng biến thiên chính bằng giá trị tuyệt đối của hệ số hồi quy từng phần.

\section{Khu vực nghiên cứu và dữ liệu}

\subsection{Khu vục nghiên cứu}

Khu vực nghiên cứu được thực hiện trên địa bàn 03 phường của quận Cầu Giấy là Quan Hoa, Dịch Vọng và Dịch Vọng Hậu. Khu vực này có một số dự án phát triển hạ tầng giao thông đô thị được thực hiện từ vài năm trở lại đây, tiêu biểu là dự án đường sắt đô thị tuyến số 03 , dự án đường Trần Đăng Ninh kéo dài và dự án đường Nguyễn Văn Huyên kéo dài (Hình 2). Dự án tuyến đường sắt số 03 bắt đầu tại ga Nhổn ở quận Bắc Từ Liêm và kết thúc ở ga Hà Nội thuộc quận Đống Đa, đi qua 12 ga. Trên địa bàn nghiên cứu, tuyến số 03 đi qua 3 ga trên cao: ga Đại học Quốc gia Hà Nội, ga Chùa Hà, và ga Cầu Giấy. Hiện nay, dự án này vẫn trong giai đoạn thi công. Dự án đường Trần Đăng Ninh kéo dài (nay là đường Khúc Thừa Dụ) được thực hiện trong giai đoạn 2014 - 2017 [21], dự án đường Nguyễn Văn
Huyên kéo dài (đoạn từ bảo tàng Dân tộc học đến đường Cầu Giấy) được thực hiện trong giai đoạn 2014-2015 [22] và đều đã đi vào hoạt động.

Trên địa bàn nghiên cứu có 23 tuyến đường, trong đó có 04 tuyến cấp 3 và 19 tuyến cấp 4 theo bảng phân loại đường phố tại quận Cầu Giấy [23]. Ngoài ra, khu vực nghiên cứu còn có một số trường đại học lớn như Đại học Quốc gia Hà Nội, Đại học Sư phạm Hà Nội; các công viên Nghĩa Đô, Cầu Giấy; và một số ngôi chùa, trong đó có chùa Hà là ngôi chùa khá nổi tiếng.

\subsection{Dũ liệu}

Dữ liệu bản đồ được thu thập là bản đồ địa chính dạng số tỷ lệ 1:500 thành lập năm 2018 của 3 phường Quan Hoa, Dịch Vọng và Dịch Vọng Hậu.

Dữ liệu giá đất thị trường được thu thập từ cuộc điều tra khảo sát thực hiện từ tháng 12/2018 đến tháng 3/2019. Ở Việt Nam, việc tiếp cận các thông tin liên quan đến thửa đất hiện còn đang hạn chế theo các kênh thông tin chính thống. Vì vậy, thông tin chủ yếu được thu thập từ việc hỏi trực tiếp chủ nhà đất, hoặc thông qua đối tượng trung gian như người hàng xóm, trung tâm môi giới bất động sản. Kết quả điều tra tại 3 phường được thống kê tại Bảng 1. Bởi phần lớn các dự án phát triển hạ tầng giao thông được thực hiện từ năm 2014, nên nghiên cứu giới hạn khoảng thời gian điều tra giao dịch từ năm 2013 trở lại đây. Sau khi lọc loại bỏ một số mẫu không đáp ứng đủ điều kiện, tổng số mẫu được sử dụng là 161 mẫu. Hình 2 mô tả phân bố của các điểm mẫu điều tra trên địa bàn nghiên cứu.

\section{Kết quả nghiên cứu và thảo luận}

\section{1. Đề xuất mô hình}

Trước khi đề xuất mô hình, nghiên cứu tiến hành kiểm tra phân phối chuẩn của biến phụ thuộc là giá đất bằng biểu đồ với đường cong chuẩn (Histograms with normal curve) trong SPSS (Hình 3 và Bảng 2). 
Bảng 1. Thống kê số lượng mẫu điều tra thu thập được

\begin{tabular}{|c|c|c|c|c|c|c|c|c|}
\hline \multirow{2}{*}{ STT } & \multirow{2}{*}{ Tên phường } & \multirow{2}{*}{$\begin{array}{c}\text { Số } \\
\text { lượng } \\
\text { mâ̂u }\end{array}$} & \multirow{2}{*}{$\begin{array}{c}\text { Giá đất cao } \\
\text { nhất (triệu } \\
\text { đồng/m²) }\end{array}$} & \multirow{2}{*}{$\begin{array}{c}\text { Giá đất thấp } \\
\text { nhất (triệu } \\
\text { đồng/m²) }\end{array}$} & \multicolumn{4}{|c|}{ Số lượng mẫu theo vị trí (VT) } \\
\hline & & & & & VT1 & VT2 & VT3 & VT4 \\
\hline 1 & Quan Hoa & 43 & 360 & 50 & 12 & 10 & 11 & 10 \\
\hline 2 & Dịch Vọng & 62 & 350 & 76 & 16 & 19 & 13 & 14 \\
\hline 3 & Dịch Vọng Hậu & 56 & 261 & 43 & 13 & 20 & 11 & 12 \\
\hline & Tổng & 161 & & & 41 & 49 & 35 & 36 \\
\hline
\end{tabular}

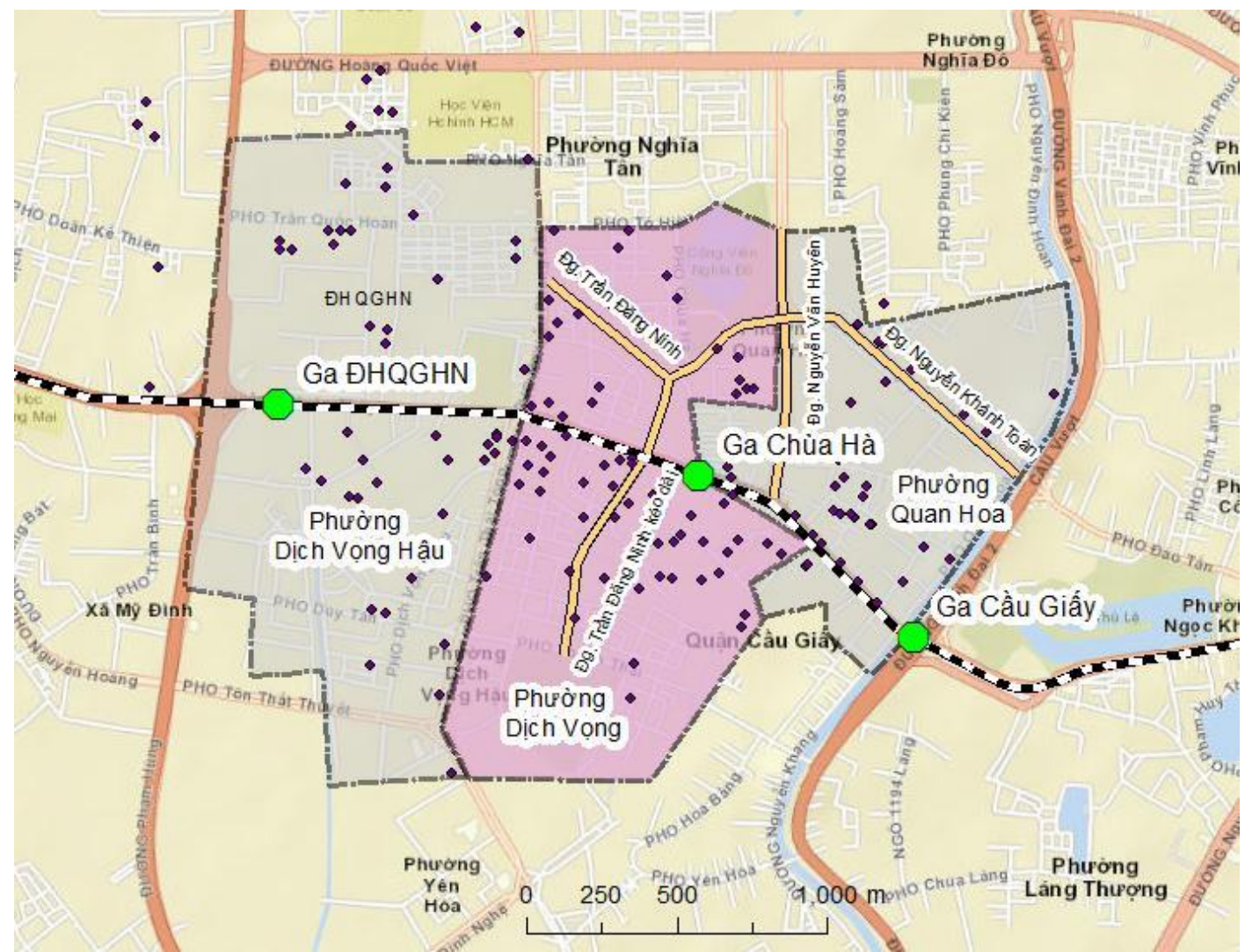

Hình 2. Khu vực nghiên cứu và phân bố của các mẫu điều tra (chấm đen hình vuông).

Bảng 2. Một số giá trị thống kê của kiểm tra phân phối chuẩn

\begin{tabular}{|c|c|c|c|c|c|}
\hline Tổng số mẫu & Trung bình & Trung vị & Độ lệch chuẩn & Độ xiên & $\begin{array}{c}\text { Sai số chuẩn của độ } \\
\text { xiên }\end{array}$ \\
\hline 161 & 163,25 & 152,36 & 74,70 & 0,54 & 0,19 \\
\hline
\end{tabular}




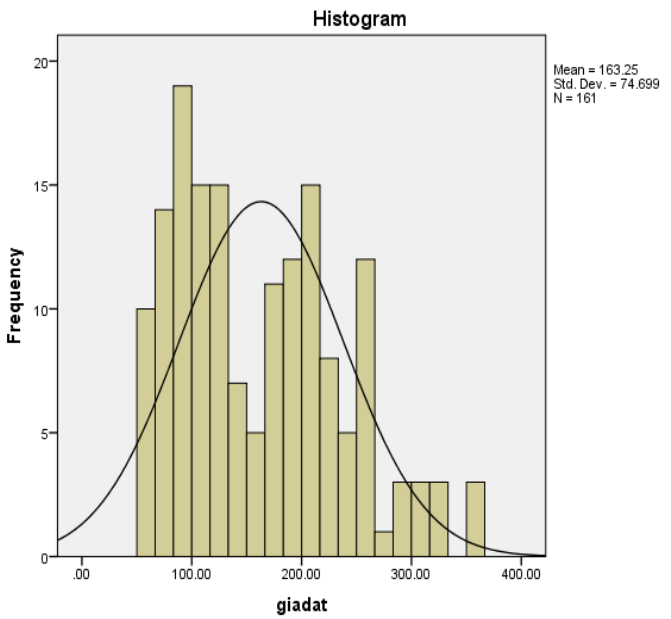

Hình 3. Biểu đồ phân phối của giá đất ở khu vực nghiên cứu.

Kết quả cho thấy phân phối này có trị trung bình (Mean) là 163,25, trung vị (Median) là 152,36, độ xiên (skewness) là 0,54 (dao động trong khoảng từ -1 đến 1 ). Về tổng thể, biểu đồ phân phối với đường cong chuẩn có dạng hình chuông. Như vậy có thể nhận xét biến giá đất có phân phối gần giống phân phối chuẩn.

Từ việc kiểm tra phân phối chuẩn của biến giá đất, mô hình ước tính giá đất được sử dụng là mô hình tuyến tính đa biến cổ điển có dạng:

$$
\text { giadat }=\alpha+\beta_{1} \mathrm{X}_{1}+\beta_{2} \mathrm{X}_{2}+\cdots+\beta_{k} \mathrm{X}_{k}
$$
trong đó biến phụ thuộc là giadat (giá đất ở đô thị trên $1 \mathrm{~m}^{2}$ ), đơn vị: triệu đồng/ $\mathrm{m}^{2}$. Biến độc lập là $X_{1} \ldots X_{k}$ và các hệ số hồi quy $\beta_{1} \ldots \beta_{k}$.

Căn cứ vào đặc thù của khu vực nghiên cứu, số lượng mẫu điều tra thực địa và tổng quan các kết quả nghiên cứu trước đây, nhóm tác giả dự kiến 11 biến đưa vào mô hình như trong Bảng 3 .

Bảng 3. Danh sách các biến được đề xuất trong mô hình

\begin{tabular}{|c|c|c|c|c|c|}
\hline STT & Tên biến & $\begin{array}{c}\text { Đơn } \\
\text { vị }\end{array}$ & Mô tả & $\begin{array}{c}\text { Dấu kỳ } \\
\text { vọng }\end{array}$ & Cách xác định \\
\hline 1 & Vị trí (vitri) & & $\begin{array}{l}4 \text { vị trí theo quy định của nhà nước }(1,2 \text {, } \\
3,4)\end{array}$ & - & $\begin{array}{l}\text { Công cụ Select by Location } \\
\text { giữa lớp thửa đất và đường } \\
\text { giao thông }\end{array}$ \\
\hline 2 & $\begin{array}{l}\text { Cấp đường } \\
\text { (capduong) }\end{array}$ & & $\begin{array}{l}4 \text { cấp đường theo quy định của nhà nước } \\
(1,2,3,4)\end{array}$ & - & \\
\hline 3 & $\begin{array}{l}\text { Năm giao dịch } \\
\text { (namgdich) }\end{array}$ & & Năm thực hiện giao dịch & + & \\
\hline 4 & $\begin{array}{l}\text { Khoảng cách đến } \\
\text { công viên gần nhất } \\
(\text { cvien })\end{array}$ & $\mathrm{m}$ & $\begin{array}{l}\text { Khoảng cách từ thửa đất đến công viên } \\
\text { gần nhất theo đường giao thông, thể hiện } \\
\text { mức độ tiếp cận đến công viên }\end{array}$ & - & \multirow{5}{*}{$\begin{array}{l}\text { Phân tích theo lộ trình của } \\
\text { đường giao thông bằng công } \\
\text { cụ Closest Facility trong } \\
\text { phần mềm ArcGIS }\end{array}$} \\
\hline 5 & $\begin{array}{l}\text { Khoảng cách đến } \\
\text { bệnh viện gần nhất } \\
(\text { bvien })\end{array}$ & $\mathrm{m}$ & $\begin{array}{l}\text { Khoảng cách từ thửa đất đến bệnh viện, } \\
\text { phòng khám đa khoa gần nhất theo đường } \\
\text { giao thông, thể hiện mức độ tiếp cận đến } \\
\text { bệnh viện }\end{array}$ & - & \\
\hline 6 & $\begin{array}{l}\text { Khoảng cách đến } \\
\text { trường học gần nhất } \\
\left(t \_h o c\right)\end{array}$ & $\mathrm{m}$ & $\begin{array}{l}\text { Khoảng cách từ thửa đất đến trường học } \\
\text { gần nhất theo đường giao thông (bao } \\
\text { gồm các bậc từ mầm non đến đại học), } \\
\text { thể hiện mức độ tiếp cận đến trường học }\end{array}$ & - & \\
\hline 7 & $\begin{array}{l}\text { Khoảng cách đến } \\
\text { chùa gấn nhất (chua) }\end{array}$ & $\mathrm{m}$ & $\begin{array}{l}\text { Khoảng cách từ thửa đất đến đất tôn } \\
\text { giáo, tín ngường (chùa, đình, đền,...) gần } \\
\text { nhất theo đường giao thông }\end{array}$ & $?$ & \\
\hline 8 & $\begin{array}{l}\text { Khoảng cách đến } \\
\text { trạm giao thông công } \\
\text { cộng gần nhất } \\
(\text { gthong_cc) }\end{array}$ & $\mathrm{m}$ & $\begin{array}{l}\text { Khoảng cách từ thửa đất đến trạ́m xe } \\
\text { buýt, nhà ga đường sắt gần nhất theo } \\
\text { đường giao thông, thể hiện mức độ tiếp } \\
\text { cận đến các loại hình giao thông công } \\
\text { cộng }\end{array}$ & - & \\
\hline 9 & $\begin{array}{l}\text { Khoảng cách đến } \\
\text { đường sắt (duongsat) }\end{array}$ & $\mathrm{m}$ & $\begin{array}{l}\text { Khoảng cách từ thửa đất đến tuyến } \\
\text { đường sắt theo đường chim bay }\end{array}$ & $?$ & $\begin{array}{l}\text { Công cư Euclidean Distance } \\
\text { trong phần mềm ArcGIS }\end{array}$ \\
\hline 10 & Tiếng ồn (tiengon) & $\mathrm{dB}$ & Tiếng ồn & $?$ & \multirow{2}{*}{$\begin{array}{l}\text { Nội suy bằng phần mềm } \\
\text { ArcGIS }\end{array}$} \\
\hline 11 & Bụi lơ lửng (bui) & $\mu \mathrm{g} / \mathrm{m}^{3}$ & Nồng độ bụi lơ lửng & $?$ & \\
\hline
\end{tabular}


Bảng 4. Kết quả phân tích hồi quy lần 1

\begin{tabular}{|c|c|c|c|c|c|c|c|}
\hline Mô hình & $\begin{array}{c}\text { Hệ số hồi quy } \\
\text { B }\end{array}$ & $\begin{array}{l}\text { Độ lệch } \\
\text { chuẩn }\end{array}$ & $\begin{array}{c}\text { Hệ số chuẩn } \\
\text { hóa Beta }\end{array}$ & $\begin{array}{l}\text { Thống } \\
\text { kê t }\end{array}$ & $\begin{array}{c}\text { Mức ý } \\
\text { nghĩa Sig. }\end{array}$ & Tolerance & VIF \\
\hline (Constant) & $-17319,304$ & 7089,792 & & $-2,443$ & 0,016 & & \\
\hline vitri & $-37,688$ & 5,141 & $-0,503$ & $-7,331$ & 0,000 & 0,763 & 1,310 \\
\hline capduong & $-18,894$ & 17,899 & $-0,074$ & $-1,056$ & 0,293 & 0,734 & 1,363 \\
\hline namgdich & 8,429 & 3,516 & 0,151 & 2,397 & 0,018 & 0,902 & 1,109 \\
\hline bvien & 0,116 & 0,030 & 0,395 & 3,907 & 0,000 & 0,351 & 2,851 \\
\hline t_hoc & 0,054 & 0,033 & 0,105 & 1,621 & 0,108 & 0,852 & 1,174 \\
\hline duongsat & $-0,091$ & 0,045 & $-0,257$ & $-2,041$ & 0,043 & 0,227 & 4,409 \\
\hline chua & $-0,077$ & 0,028 & $-0,206$ & $-2,760$ & 0,007 & 0,645 & 1,550 \\
\hline cvien & $-0,062$ & 0,018 & $-0,289$ & $-3,338$ & 0,001 & 0,481 & 2,080 \\
\hline gthong_cc & $-0,086$ & 0,033 & $-0,202$ & $-2,596$ & 0,011 & 0,592 & 1,689 \\
\hline tiengon & 12,646 & 7,369 & 0,679 & 1,716 & 0,089 & 0,023 & 43,604 \\
\hline bui & $-0,699$ & 0,408 & $-0,679$ & $-1,714$ & 0,089 & 0,023 & 43,619 \\
\hline $\mathrm{R}^{2}$ & & & & & 0,554 & & \\
\hline $\mathrm{R}^{2}$ điều chỉnh & & & & & 0,515 & & \\
\hline
\end{tabular}

Bảng 5. Kết quả hồi quy lần 2

\begin{tabular}{|l|r|r|r|r|r|r|r|}
\hline \multicolumn{1}{|c|}{ Mô hình } & $\begin{array}{r}\text { Hệ số hồi quy } \\
\mathrm{B}\end{array}$ & $\begin{array}{c}\text { Độ lệch } \\
\text { chuần }\end{array}$ & $\begin{array}{c}\text { Hệ số chuẩn } \\
\text { hóa Beta }\end{array}$ & $\begin{array}{c}\text { Thống kê } \\
\mathrm{t}\end{array}$ & $\begin{array}{c}\text { Mức ý } \\
\text { nghĩa Sig. }\end{array}$ & Tolerance & VIF \\
\hline (Constant) & $-18313,597$ & 6999,799 & & $-2,616$ & 0,010 & & \\
\hline vitri & $-37,582$ & 4,767 & $-0,502$ & $-7,885$ & 0,000 & 0,888 & 1,126 \\
\hline namgdich & 9,260 & 3,471 & 0,166 & 2,668 & 0,009 & 0,926 & 1,080 \\
\hline bvien & 0,124 & 0,027 & 0,420 & 4,568 & 0,000 & 0,426 & 2,349 \\
\hline duongsat & $-0,116$ & 0,028 & $-0,329$ & $-4,093$ & 0,000 & 0,558 & 1,793 \\
\hline chua & $-0,053$ & 0,023 & $-0,142$ & $-2,244$ & 0,027 & 0,902 & 1,109 \\
\hline cvien & $-0,070$ & 0,015 & $-0,327$ & $-4,524$ & 0,000 & 0,686 & 1,457 \\
\hline gthong_cc & $-0,107$ & 0,030 & $-0,251$ & $-3,511$ & 0,001 & 0,702 & 1,425 \\
\hline Mô hình & $\mathrm{R}$ & $\mathrm{R}^{2}$ & $\mathrm{R}^{2}$ hiệu chỉnh & \multicolumn{7}{c|}{ Độ lệch chuẩn } & \multicolumn{2}{c|}{ Durbin-Watson } \\
\hline & $0,732^{\mathrm{a}}$ & 0,536 & 0,511 & \multicolumn{5}{c|}{54,35803} & \multicolumn{2}{c|}{1,284} \\
\hline
\end{tabular}




\subsection{Phân tích hồi quy}

Kết quả của phân tích hồi quy lần đầu của mô hình ở mục 4.1 với tất cả 11 biến được thể hiện ở Bảng 4.

Kết quả hồi quy lần đầu cho thấy biến capduong, $\mathrm{t}$ hoc, tiengon, bui là những biến có giá trị Sig. $>0,05$, tức là không có ý nghĩa thống kê nên được loại bỏ. Mô hình còn lại có 7 biến và được phân tích hồi quy lần 2 (Bảng 5).

Mô hình hồi quy lần 2 được giải thích bởi 7 biến đều có ý nghĩa thống kê và không có hiện tượng đa cộng tuyến do giá trị VIF của các hệ số hồi quy nhỏ hơn 10. Để kiểm định vấn đề tự tương quan, nghiên cứu xét đến giá trị DurbinWatson $(d=1,284)$. Tra bảng giá trị phân phối của thống kê Durbin-Watson với mức ý nghĩa 0,05 , ta được các giá trị tới hạn $d_{L}=1,637$, $d_{U}=1,832$ [19]. Như vậy $d<d_{L}$, tức có hiện tượng tự tương quan xảy ra. Vấn đề này sẽ được khắc phục ở phần sau của mục này.

Mô hình cổ điển giả định rằng sai số ngẫu nhiên của một mẫu quan sát nào đó (đặt là $U_{i}$ ) đều không bị ảnh hưởng bởi sai số ngẫu nhiên liên quan tới một quan sát khác. Tuy nhiên, nếu có một sự phụ thuộc như vậy thì có quan hệ tự tương quan. Giả sử $U_{i}$ có mô hình hồi quy bậc 1 , tức là chỉ có giá trị $U_{i}$ và giá trị ngay trước đó $\left(U_{i-1}\right)$ là có liên quan, tức độ trễ là 1 :

$$
U_{i}=\rho U_{i-1}+\varepsilon_{i}
$$

trong đó $-1<\rho<1$ và $\varepsilon_{i}$ tuân theo các giả định của phương pháp số bình phương nhỏ nhất, cụ thể là kỳ vọng bằng 0 , phương sai không đổi và không tự tương quan.

Để khắc phục hiện tượng tự tương quan, nghiên cứu ứng dụng phương pháp sai phân với quy trình gồm các bước: 1 ) Tính giá trị $\rho$ (bằng phần mềm Eview); 2) Tạo biến mới và gán giá trị sai phân cho tất cả các biến trong mô hình trên SPSS; 3) Phân tích hồi quy với các giá trị của biến mới.
1. Trên phần mềm Eview, sử dụng công cụ Serial Correlation LM Test (nhóm công cụ Residual Diagnostics) để tiến hành kiểm định giả thuyết tồn tại tương quan bậc 1 của sai số ngẫu nhiên. Trên cơ sở đó, xác định hệ số hồi quy $\rho$ của biến $U_{i-1}$ là 0,374571 .

2. Tạo biến mới và gán giá trị sai phân (difference) của các biến có trong mô hình trên phần mềm SPSS. Các biến mới được gán với công thức sai phân như sau:

$$
\text { giadatNew }_{i}=\text { giadat }_{i}-\rho_{\times} \text {giadat }_{i-1}
$$

Tương tự, ta có các biến mới vitriNew, namgdichNew, bvienNew, duongsatNew, chuaNew, cvienNew, gthong_ccNew với giá trị là sai phân của các biến cũ.

3. Phân tích hồi quy với các biến mới

Sau khi thực hiện phân tích hồi quy với các biến mới và lọc mức ý nghĩa thống kê của các biến, kết quả được thể hiện ở Bảng 6. Biến chuaNew do có giá trị Sig. không đáp ứng điều kiện nên bị loại khỏi mô hình.

Giá trị Durbin-Watson là 1,920. Tra bảng giá trị Durbin-Watson với số biến độc lập là 6 , thì $d_{L}=1,651, d_{U}=1,817$. Như vậy $d_{U}<d<4-d_{U}$ nên hiện tượng tự tương quan không còn xảy ra.

Giá trị $\mathrm{R}^{2}$ hiệu chỉnh là 0,510 thể hiện mô hình phù hợp với tập dữ liệu ở mức $51 \%$. Nói cách khác, $51 \%$ sự biến thiên của giá đất ở đô thị tại khu vực nghiên cứu được giải thích bởi 6 biến là vị trí, năm giao dịch, khoảng cách từ thửa đất đến bệnh viện gần nhất, khoảng cách từ thửa đất đến đường sắt, khoảng cách từ thửa đất đến công viên gần nhất, và khoảng cách từ thửa đất đến trạm giao thông công cộng gần nhất.

Mô hình được viết tổng thể như sau:

GiadatNew $=7,180_{\times}$namgdichNew
$39,843_{\times}$vitriNew $\quad+$
$0,105_{\times}$duongsatNew $-0,094 \times$ bvienNew -
$0,068_{\times}$gthong_ccNew $-8851,641$


Bảng 6. Kết quả mô hình sau khi khắc phục hiện tượng tự tương quan

\begin{tabular}{|l|r|r|r|r|r|r|r|}
\hline \multicolumn{1}{|c|}{ Mô hình } & $\begin{array}{c}\text { Hệ số hồi } \\
\text { quy B }\end{array}$ & $\begin{array}{c}\text { Độ lệch } \\
\text { chuẩn }\end{array}$ & $\begin{array}{c}\text { Hệ số chuẩn } \\
\text { hóa Beta }\end{array}$ & $\begin{array}{c}\text { Thống kê } \\
\text { t }\end{array}$ & $\begin{array}{c}\text { Mức ý } \\
\text { nghĩa Sig. }\end{array}$ & Tolerance & VIF \\
\hline (Constant) & $-8851,641$ & 4042,981 & & $-2,189$ & 0,030 & & \\
\hline vitriNew & $-39,843$ & 4,284 & $-0,595$ & $-9,300$ & 0,000 & 0,899 & 1,113 \\
\hline namgdichNew & 7,180 & 3,205 & 0,142 & 2,240 & 0,027 & 0,922 & 1,084 \\
\hline bvienNew & 0,094 & 0,026 & 0,315 & 3,583 & 0,000 & 0,477 & 2,095 \\
\hline duongsatNew & $-0,105$ & 0,028 & $-0,291$ & $-3,737$ & 0,000 & 0,609 & 1,643 \\
\hline cvienNew & $-0,056$ & 0,018 & $-0,210$ & $-3,185$ & 0,002 & 0,843 & 1,186 \\
\hline gthong_ccNew & $-0,068$ & 0,033 & $-0,147$ & $-2,064$ & 0,041 & 0,721 & 1,388 \\
\hline Mô hình & $\mathrm{R}$ & $\mathrm{R}^{2}$ & $\mathrm{R}^{2}$ hiệu chỉnh & \multicolumn{2}{|c|}{ Độ lệch chuẩn } & \multicolumn{2}{c|}{ Durbin-Watson } \\
\hline & $0,730^{\mathrm{a}}$ & 0,532 & 0,510 & \multicolumn{3}{|c|}{50,24839} & \multicolumn{2}{|c|}{1,920} \\
\hline
\end{tabular}

\subsection{Phân tích ảnh hưởng của dụ án phát triển giao thông đô thị đến giá đất ở khu vực nghiên cưu}

Để phân tích ảnh hưởng của 6 yếu tố nói chung và của các yếu tố liên quan đến hạ tầng giao thông đô thị nói riêng cần dựa trên hệ số hồi quy của các biến độc lập. Theo dấu của hệ số hồi quy thì những biến có chiều hướng ảnh hưởng thuận đến giá đất là năm giao dịch, khoảng cách từ thửa đất đến bệnh viện gần nhất. Những biến còn lại là vị trí, khoảng cách từ thửa đất đến đường sắt, khoảng cách từ thửa đất đến công viên và khoảng cách từ thửa đất đến trạm giao thông công cộng có chiều hướng ảnh hưởng nghịch đến giá đất. Cụ thể như sau:

- Biến vị trí: Khi các yếu tố khác không đổi, các thửa đất ở vị trí 1 có giá cao nhất và giảm dần ở các vị trí 2, 3 và 4 (chênh lệch khoảng 40 triệu đồng/ $/ \mathrm{m}^{2}$ khi vị trí tăng/giảm 1 bậc).

- Năm giao dịch: Khi các yếu tố khác không đổi, các thửa đất có năm giao dịch sau sẽ cao hơn các thửa đất có năm giao dịch trước đó khoảng 7,2 triệu đồng $/ \mathrm{m}^{2}$.

- Khoảng cách từ thửa đất đến bệnh viện gần nhất: Khi các yếu tố khác không đổi, những thửa đất có khoảng cách đến bệnh viện gần nhất tăng thì giá đất sẽ tăng và ngược lại (chênh lệch khoảng 9,4 triệu đồng $/ \mathrm{m}^{2}$ khi khoảng cách tăng/giảm $100 \mathrm{~m})$. Điều này thể hiện tác động môi trường do bệnh viện gây ra (tiêu cực) lớn hơn mức độ tiếp cận đến bệnh viện (tích cực).
- Khoảng cách từ thửa đất đến đường sắt: Khi các yếu tố khác không đổi, những thửa đất có khoảng cách đến đường sắt tăng thì giá đất sẽ giảm và ngược lại (chênh lệch khoảng 10,5 triệu đồng $/ \mathrm{m}^{2}$ khi khoảng cách tăng/giảm 100m).

- Khoảng cách từ thửa đất đến công viên gần nhất: Khi các yếu tố khác không đổi, những thửa đất có khoảng cách đến công viên gần nhất tăng thì giá đất sẽ giảm và ngược lại (chênh lệch khoảng 5,6 triệu đồng $/ \mathrm{m}^{2}$ khi khoảng cách tăng/giảm $100 \mathrm{~m})$. Điều này thể hiện mức độ tiếp cận đến công viên là yếu tố ảnh hưởng tích cực đến giá đất bởi càng gần công viên thì giá đất có xu hướng cao hơn.

- Khoảng cách từ thửa đất đến trạm giao thông công cộng gần nhất: Khi các yếu tố khác không đổi, các thửa đất có khoảng cách đến trạm giao thông công cộng gần nhất tăng thì giá đất giảm và ngược lại (chênh lệch khoảng 6,8 triệu đồng $/ \mathrm{m}^{2}$ khi khoảng cách tăng/giảm $100 \mathrm{~m}$ ).

Trong số các biến trên thì những biến liên quan đến dự án phát triển hạ tầng cơ sở giao thông là 3 biến vị trí, khoảng cách từ thửa đất đến đường sắt, và khoảng cách từ thửa đất đến trạm giao thông công cộng. Khu vực nghiên cứu có 2 dự án điển hình là đường Trần Đăng Ninh kéo dài và đường Nguyễn Văn Huyên kéo dài. Việc mở rộng đường đã tạo cơ hội cho nhiều thửa đất đang ở vị trí trong ngõ (vị trí 2, 3 hoặc 4) được tiếp giáp với đường lớn thành vị trí 1 , thuận tiện 
hơn và tạo ra nhiều lợi thế hơn. Hai tuyến đường này đều thuộc cấp 3 trong danh mục phân cấp của Nhà nước, vì vậy sự thay đổi giá đất khi mở rộng đường sẽ chủ yếu do sự thay đổi vị trí của thửa đất. Những thửa đất xung quanh khu vực này khi được mở rộng đường sẽ được tăng từ khoảng 40 triệu đồng $/ \mathrm{m}^{2}$ cho đến 119 triệu đồng $/ \mathrm{m}^{2}$.

Đối với dự án tuyến đường sắt đô thị số 03 đoạn đi qua khu vực nghiên cứu thì có mức độ ảnh hưởng theo chiều hướng nghịch đến giá đất vì hệ số hồi quy mang dấu âm. Theo giá trị của hệ số hồi quy ở mô hình trên, những thửa đất càng gần với đường sắt thì có giá sẽ cao hơn so với những thửa đất ở xa (chênh lệch khoảng 10,5 triệu đồng $/ \mathrm{m}^{2}$ khi khoảng cách tăng/giảm $100 \mathrm{~m}$ ). Điều này thể hiện tác động tích cực từ việc dễ dàng tiếp cận với đường sắt lớn hơn tác động tiêu cực (như tiếng ồn) do đường sắt gây ra. Thực tế, trường hợp nghiên cứu của bài báo này có thể được giải thích một phần bởi lý do sau: 1) tuyến đường sắt đô thị này là đường trên cao và chạy dọc trên đường Xuân Thủy, Cầu Giấy, Kim Mã đều là những tuyến đường lớn. Những thửa đất có khoảng cách gần với đường sắt thì cũng có khoảng cách gần với những tuyến đường này nên sự ảnh hưởng về vị trí đó cũng là một phần làm giá đất tăng; và 2) dự án tuyến đường sắt số 03 vẫn đang trong giai đoạn thực hiện, tiến độ bị chậm so với kế hoạch ban đầu. Chính vì vậy, ảnh hưởng tiếng ồn từ khoảng cách của thửa đất đến đường sắt chưa được xem xét đầy đủ vì hiện tại chưa có tuyến tàu chạy.

Khoảng cách từ thửa đất đến trạm giao thông công cộng gần nhất cũng là một trong số các biến có ảnh hưởng tích cực đến giá đất trên địa bàn nghiên cứu. Như vậy khả năng tiếp cận với các loại hình giao thông công cộng (trạm xe buýt, nhà ga đường sắt) góp phần ảnh hưởng đến giá đất khu vực xung quanh. Điều này có thể hiểu được vì mạng lưới xe buýt trên địa bàn quận Cầu Giẩy là dày đặc với 59 tuyến xe buýt hoạt động ổn định từ lâu. Các trạm chờ xe phần lớn được bố trí ở những địa điểm đông dân cư và tạo thuận lợi cho hành khách tiếp cận với những địa điểm kinh tế xã hội khác như trường học, các cơ quan, các khu trung tâm thương mại,... Trong tương lai, mạng lưới xe buýt này cùng với hệ thống nhà ga đường sắt được hoàn thiện sẽ góp phần cải thiện hệ thống giao thông công cộng, phục vụ việc đi lại của người dân được tốt hơn.

Tuy nhiên, ngoài những mặt tích cực từ việc phát triển hạ tầng giao thông đô thị, chúng ta cũng phải tính đến những mặt tiêu cực. Một trong số những yếu tố về môi trường đó là tiếng ồn và nồng độ bụi lơ lửng. Mặc dù trong nghiên cứu này, các yếu tố đó đã bị loại ra khỏi mô hình vì có mức ý nghĩa thấp. Tuy nhiên, do số liệu hiện có chưa được đầy đủ nên cần rà soát lại 2 yếu tố này trong các nghiên cứu tiếp theo, khi các dự án giao thông đã hoàn thành.

Mức độ ảnh hưởng của dự án phát triển giao thông đô thị không chỉ thể hiện ở phạm vi tổng thể của khu vực nghiên cứu mà còn cần xem xét đến phạm vi cục bộ. Đó là những thửa đất chịu ảnh hưởng trực tiếp từ các tuyến đường được mở rộng, kéo dài. Thực tế, những yếu tố cá biệt như hình dạng, diện tích, mặt tiền của các thửa đất này có thể bị thay đồi và làm ảnh hưởng đến giá đất. Tuy nhiên, đó là những thay đổi với số lượng ít các thửa, và có thể tính toán thủ công.

\section{Kết luận, kiến nghị}

Nhìn chung, các dự án phát triển hạ tầng giao thông đô thị có xu hướng làm tăng giá trị đất đai. Đối với khu vực 3 phường Quan Hoa, Dịch Vọng và Dịch Vọng Hậu thuộc quận Cầu Giấy thì yếu tố vị trí, khoảng cách đến đường sắt, và khoảng cách đến trạm giao thông công cộng là những yếu tố có ảnh hưởng tích cực đến giá đất. Yếu tố vị trí thể hiện ở khía cạnh các thửa đất được chuyển vị trí từ vị trí 2,3 , hoặc 4 lên vị trí 1 tiếp giáp với các tuyến đường lớn như Trần Đăng Ninh kéo dài (hiện là Khúc Thừa Dụ) và Nguyễn Văn Huyên kéo dài khi các dự án này hoàn thành. Điều này khiến giá đất có thể tăng thêm từ 40 triệu đồng $/ \mathrm{m}^{2}$ đến 119 triệu đồng $/ \mathrm{m}^{2}$. Yếu tố khoảng cách từ thửa đất đến đường sắt thể hiện ở khía cạnh những thửa đất có khoảng cách đển đường sắt càng gần thì có giá cao hơn những thửa đất ở xa. Tuy nhiên, tuyến đường sắt đô thị số 03 hiện nay vẫn đang trong giai đoạn thực hiện, chính vì vậy những tác động của tuyến đường sắt vẫn chưa thực sự được rõ ràng đối với 
các bất động sản xung quanh nói chung và thửa đất nói riêng. Yếu tố khoảng cách từ thửa đất đến trạm giao thông công cộng gần nhất thể hiện khả năng tiếp cận với các loại hình giao thông công cộng cũng làm giá đất tăng.

Khi lượng hóa được khoản giá trị tăng thêm của đất từ việc phát triển hạ tầng giao thông đô thị thì chúng ta có thể có những đề xuất về mặt chính sách cho các giải pháp thu nhận giá trị đất (Land Value Capture - LVC). Trong những năm gần đây, việc nâng cao giá trị đất và thu nhận giá trị đất đang ngày càng thu hút sự chú ý như một phương tiện tài chính tiềm năng cho sự phát triển cơ sở hạ tầng giao thông, khi mà các dự án này thường xảy ra tình trạng bị thiếu vốn. Ngoài ra, việc xác định giá trị tăng thêm một cách rõ ràng là một trong những bằng chứng để tạo điều kiện đảm bảo cho sự công bằng giữa nhà nước và người dân, cũng như giữa những người dân với nhau trong vấn đề bồi thường, giải phóng mặt bằng.

\section{Lời cảm ơn}

Nghiên cứu này được tài trợ bởi Đại học Quốc gia Hà Nội trong đề tài mã số QG.19.14 "Nghiên cứu xác định giá đất ở tại đô thị trong mối quan hệ với vị thế, chất lượng môi trường và dịch vụ hệ sinh thái trên địa bàn thành phố Hà Nội”.

\section{Tài liệu tham khảo}

[1] R. Tan, et al., The effect of new metro stations on local land use and housing prices: The case of Wuhan, China, Journal of Transport Geography 79 (2019) 1-17. https://doi.org/10.1016/j.jtrangeo.2019. 102488

[2] G. Debrezion, E. Pels, P. Rietveld, The Impact of Railway Stations on Residential and Commercial Property Value: A Meta-analysis, The Journal of Real Estate Finance and Economics 35 (2007) 161-180. https://doi.org/10.1007/s11146-0079032-z

[3] H. Du, C. Mulley, Understanding spatial variations in the impact of accessibility on land value using geographically weighted regression, Journal of Transport and Land Use 5 (2012) 46-
59. https://doi.org/10.5198/jtlu.v5i2.225

[4] H. Chen, A. Rufolo, K. Dueker, Measuring the Impact of Light Rail Systems on Single Family Home Values: A Hedonic Approach with GIS Application, Center for Urban Studies Publications and Reports, Portland State University, Portland (1997).

[5] J.B. Ingvardson, O.A. Nielsen, Effects of new bus and rail rapid transit systems-an international review, Transport Reviews 38 (2018) 96-116. https://doi.org/10.1080/01441647.2017.1301594.

[6] P. Lawless, T. Gore, Urban Regeneration and Transport Investment: A Case Study of Sheffield 1992-96, Urban Studies 36 (1999) 527-545. https://doi.org/10.1080/0042098993510.

[7] N.M. Hung, et al., Property valuation methodology applied by Status - Quality Trade Off, Land Administration Magazine 06 (2008) (in Vietnamese).

[8] N.Q. Hoa, N.H. Duong, Mass appraisal of land value in Go Vap district, Ho Chi Minh city, Economics Development Magazine 26 (2016) 82103 (in Vietnamese).

[9] L.P. Thuy, P.L. Tuan, T.Q. Binh, Application of Space Syntax and GIS in Assessment of Accessibility Factors Affecting Urban Residential Land Value (a Case Study in Trung Hoa - Nhan Chinh Area, Hanoi City), FIG Working week 2019 "Geospatial information for a smarter life and environmental resilience", Hanoi, Vietnam (2019)

[10] H. Du, C. Mulley, The short-term land value impacts of urban rail transit: Quantitative evidence from Sunderland, UK, Land Use Policy 24 (2007) 223-233. https://doi.org/10.1016/j.landusepol. 2005.12.003.

[11] People's Committee of Hanoi, Decision to promulgate regulations on land prices in Hanoi, valid from $1 / 1 / 2015$ to $31 / 12 / 2019$, Hanoi, 2014 (in Vietnamese).

[12] A.B. Morancho, A Hedonic valuation of urban green areas, Landscape and Urban planning 66 (2003) 35-41. https://doi.org/10.1016/S01692046(03)00093-8.

[13] A. Król, Application of Hedonic methods in modelling real estate prices in Poland, B. Lausen et al. (eds), Data science, learning by latent structures, and knowledge discovery, Springer, Berlin, Heidelberg (2015) 501-511. https://doi.org/10.1007/978-3-662-44983-7_44.

[14] S.B. Green, How many subjects does it take to do a regression analysis, Multivariate Behavioral 
Research 26 (1991) 499-510. https://doi.org/10. 1207/s15327906mbr2603 7.

[15] S. Malpezzi, Hedonic Pricing Models: A selective and applied review, Housing Economics and Public Policy (2002) 67-89. https://doi.org/10.1002/9780470690680.ch5.

[16] B.N. Tuan, Research on some reasons of urban land price changing and propose appropriate land valuation method in Vietnam, Report of the Institute of Cadastre Research, 2004 (in Vietnamese).

[17] Department of Natural Resources and Environment in Cau Giay district, Report on environmental protection in 2018 in Cau Giay district, Hanoi, 2018 (in Vietnamese).

[18] F.H.J. Joseph, et al., Multivariate Data Analysis (7th edition), Pearson, United States of America, 2014.

[19] N.E. Savin, K.J. White, The Durbin-Watson Test for Serial Correlation with Extreme Sample Sizes or Many Regressors, Econometrica 45 (1977) 1989-1996.

[20] D.N. Gujarati, Basic Econometrics (4th Edition), Gary Burke, New York, 2004.

[21] People's Committee of Hanoi, Decision No.7468/QD-UBND dated 9/12/2013 approving the Tran Dang Ninh Str. extended project, Cau Giay district, Hanoi city, Hanoi, 2013 (in Vietnamese).

[22] People's Committee of Hanoi, Decision No.2542/QD-UBND dated 8/6/2012 approving of Construction the road from the Museum of Ethnology to Cau Giay road, Hanoi, 2012 (in Vietnamese).

[23] People's Committee of Hanoi, Decision No.31/2010/QD-UBND approving of the issuance of street classification boards in district and towns, classification of main traffic sections, and classification of commnues in Hanoi city in order to collect land taxes, Hanoi, 2010 (in Vietnamese). 